\title{
Experimental evaluation of an integrated demand response program using electric heat boosters to provide multi-system services
}

\author{
Cai, Hanmin; Thingvad, Andreas; You, Shi; Marinelli, Mattia
}

Published in:

Energy

Link to article, DOI:

10.1016/j.energy.2019.116729

Publication date:

2020

Document Version

Early version, also known as pre-print

Link back to DTU Orbit

Citation (APA):

Cai, H., Thingvad, A., You, S., \& Marinelli, M. (2020). Experimental evaluation of an integrated demand response program using electric heat boosters to provide multi-system services. Energy, 193, [116729]. https://doi.org/10.1016/j.energy.2019.116729

\section{General rights}

Copyright and moral rights for the publications made accessible in the public portal are retained by the authors and/or other copyright owners and it is a condition of accessing publications that users recognise and abide by the legal requirements associated with these rights.

- Users may download and print one copy of any publication from the public portal for the purpose of private study or research.

- You may not further distribute the material or use it for any profit-making activity or commercial gain

- You may freely distribute the URL identifying the publication in the public portal 


\begin{abstract}
The share of renewable energy resources (RES) production has been increasing in both the electricity system and the district heating (DH) system in Denmark. This challenges system operators' traditional operating practices in which different energy systems are separately managed and end-users play a passive role in the system operation. Integrated energy system operation considering multiple energy carriers is increasingly perceived as a key approach to accommodate the RES in a globally optimal way. Although existing literature has analysed demand response (DR)'s potential for improving system operation, it has been largely confined to a single energy system. To fill this gap, the current study focuses on integrated demand response (IDR)'s potential for improving the operation of integrated electricity and DH system. This paper presents one of the first experimental demonstrations of an IDR program by deploying electric heat boosters (EHBs) to provide multi-system services. The multi-scale demonstration of the IDR program was structured into three hierarchical levels: (i) augmented commercial DH substations; (ii) distributed situation-aware control systems; and (iii) an aggregation controller. The results show that EHBs in 5 single-family buildings simultaneously delivered frequency-controlled normal operation reserve (FCR-N) with a symmetric capacity of $7.5 \mathrm{~kW}$ to the electricity system with an activation time of 4 seconds and a peak shaving service to the $\mathrm{DH}$ system. The temperature distribution over the test period revealed that end-user comfort was maintained. In conclusion, EHBs in an IDR program can simultaneously support both the electricity system and the DH system, which provides system operators' a tool for integrated system operation; the multi-system service design enhances the economic outlook of active demands in an IDR program.
\end{abstract}

Keywords: Integrated demand response; Peak shaving; Frequency-controlled normal operation reserves; Electric heat booster; Low-temperature district heating

\title{
1. Introduction
}

Recent years have seen global efforts in enhancing energy systems with a high share of distributed renewable energy sources (RES) and improving energy system efficiency. There

\footnotetext{
${ }^{*}$ Corresponding author

Email addresses: hacai@elektro.dtu.dk (Hanmin Cai), athing@elektro.dtu.dk (Andreas Thingvad), sy@elektro.dtu.dk (Shi You), matm@elektro.dtu.dk (Mattia Marinelli) 
are two trends that can be seen today: wind power and photovoltaic are penetrating in the electricity system; the district heating $(\mathrm{DH})$ system is moving towards low supply temperature to reduce loss and integrate more distributed thermal energy sources [1]. That is to say, energy systems will have to accommodate a more significant amount of distributed resources than they do today. Currently, different energy systems are separately managed and the end-users play a passive role. This operating practice will no longer be sufficient to achieve a globally optimal system operation. Instead, integrated and smart energy system operation [2] [3] is increasingly perceived as a key approach to accommodate the RES optimally. More specifically, the provision of system services from the demand side and interactions across energy systems will be key to achieve integrated operation. The role of demand in the real-time operation of integrated electricity and DH system needs to be investigated to provide operators with insights into the tools available for future operating practices.

Although existing literature has examined the effectiveness of demand response (DR) programs as one way of engaging demand in system operation [4], it has been largely confined to one energy system. Douglass et al. [5] have developed decentralised controllers for electrical appliances to show that the frequency-sensitive appliances are capable of providing both frequency-controlled normal operation reserve (FCR-N) and frequency-controlled disturbance reserve (FCR-D) services to support electricity system operation. Thingvad et al. [6] have experimentally demonstrated that parked electric vehicles (EVs), with a bidirectional charger, can deliver FCR-N by adjusting their charging power according to frequency deviations from the nominal value such that they charge in the over-frequency periods and discharge in the under-frequency periods. They have also quantified that the services can generate a profit of 899 EUR per year per vehicle [7]. The FCR-N service can also be possible for unidirectional loads that can only consume power, provided that the reference power can be set to $50 \%$ of the total power rating and the power can be adjusted according to frequency deviations. This would create the same symmetry as the bidirectional loads, but a lower revenue of 52 EUR per year per vehicle is obtained for 3 hours of frequency regulation per day as it can only be delivered before the EV is fully charged. 
The DR programs in the DH system are relatively scarce and mostly about reducing thermal peak loads that often lead to a sub-optimal dispatch of combined heat and power plants (CHPs) and increase the primary energy consumption [8]. Johansson et al. [9] have deployed an agent-based load control strategy in DH substations to reduce peak demand in DH network by short-term load shifting. Guelpa et al. [10] suggest that shifting building thermal loads via a clustering approach can improve peak reduction performance by $6 \%$, allow new buildings to be connected into a congested network and increase cogeneration plants' competitiveness on the electricity market. In [11], it has been shown that integrating electric heat boosters (EHBs) in a combined electricity and heating system can reduce DH network losses by as much as 35\%; and active coordination of EHBs can significantly reduce DH peak boiler usage.

In contrast to these conventional scopes of DR, this study has focused on an integrated demand response (IDR) program that enhances end-users' roles in integrated electricity and DH system, and we provide system operators' with a tool to support integrated system operation. In this paper, we present the design and implementation of the IDR program in which EHBs increase operational flexibility for both systems. While a variety of definitions of the term IDR have been suggested, this paper will use the definition proposed by Wang et al. [12] who saw it as energy users' capabilities' of shifting both their energy consumption and the source of the consumed energy; and the term fuel shift (FS) is used referring to the changing of energy sources. The IDR program is feasible because multiple utilities are usually present in the urban area. More specifically, inside an EHB, the domestic hot water (DHW) heating demand can be supplied by both the electricity system and the DH system. The EHB has been suggested as an enabler of the low-temperature district heating (LTDH) [11] and it couples the DH system with the electricity system. Furthermore, it is possible to deliver multiple services to both systems while ensuring end-user comfort. Existing literature related to IDR is descriptive and insufficient to demonstrate the value of the IDR in a real system. Bahrami and Sheikhi [13] suggest a real-time pricing based IDR program for peak shaving in the electricity distribution network by switching to gas consumption. They argue that by switching energy sources in addition to load shifting, existing DR's dependency on end-users' role can be reduced. Wang et al. [14] propose a transactive mechanism of IDR between district energy stations and end-users to allocate energy optimally. By contrast, this study demonstrates IDR's capability of providing multiple energy system services in real-world operation.

In addition to the technical challenges of IDR, one restriction of its feasibility in the real world is its economic outlook since multiple energy conversion units are needed. In this study, five EHBs were aggregated to provide two services readily available to both DH and electricity system operators. Through detailed design and multi-scale implementation, we provide not only technical insights into the tools to support integrated system operation but also enhance the economic outlook of the IDR. We also seek to obtain quantitative metrics that existing literature lacks to support further technical and economic evaluation of such technology.

All things considered, the novel contributions of this paper are threefold. Firstly, we demonstrate that EHBs can enable LTDH while guaranteeing a sufficient amount of DHW 
and additional service provisions enhance the economic outlook of LTDH. Secondly, we bridge the gap between the IDR concept and the real-world implementation through systematic investigation of the IDR program within real-time energy system operation. Thirdly, the design of the multi-system services provides system operators with additional tools for future integrated system operation.

The rest of the paper is organised as follows. Section 2 briefly explains the peak shaving service and the FCR-N service that constitute the multi-service aspect of an IDR program. Then section 3 describes the design of the EHB and the three hierarchical levels in the multiscale implementation. Section 4 summarises the experimental findings with quantitative analysis on the service provisions and end-user comfort. Finally, section 5 concludes this paper with the implication of the findings to future research into this area.

\section{Integrated demand response}

Two services were considered in this study: a peak shaving service for the DH system; and a FCR-N service for the electricity system. The reasons for choosing these two services are as follows. Firstly, the EHB has been shown to reduce peak demands in a DH system effectively and bring substantial system-wide benefits by shifting loads from the DH system to the electricity system at the expense of a minor increase in peak power of an electricity distribution network [11]. Furthermore, since FCR-N is compensated per power capacity with relatively small energy requirements [15], it is a suitable ancillary service for small domestic appliances such as the EHB. But since the power of EHB is unidirectional, the amount of daily energy consumption is the limiting factor for how long an FCR-N service can be delivered.

\subsection{Peak shaving service for DH system}

Load peaks in the DH system are to a large degree dependent on the local conditions, and to the best of the authors' knowledge, there is no established international or national standards or market for DH peak shaving service. Nonetheless, peak shaving needs can be seen at two levels. At the system level, there are usually peak loads occurring between 06:00 and 09:00 in the morning and between 17:00 and 20:00 in the evening in the greater Copenhagen area [16]. This only occurs in the winter as can be seen in Figure 1(a) which shows the total heating demand for the Greater Copenhagen area in 2015 along with a marginal heat cost profile [17]. A load duration curve of the same year is presented in Figure 1(b). The total power peaked at $4.51 \mathrm{GW}$ while the marginal cost peaked at $0.08 \mathrm{EUR} / \mathrm{kWh}$ during winter days. Typically these peak loads are covered by natural gas boilers. To achieve a $\mathrm{CO}_{2}$ neutral DH system in Copenhagen by 2025 [18], peak loads must be avoided. At the district level, the DH network can experience peak loads and the pumping power may not be sufficient to circulate the water inside the network. As a result, a low differential pressure occurs at the critical node [19] and end users can not extract sufficient heat for DHW and space heating (SH), and their comfort is compromised. Although both DHW and SH demands can contribute to network congestion, DHW demands could play a bigger role as they are more volatile than SH demands during the day and contribute significantly to 

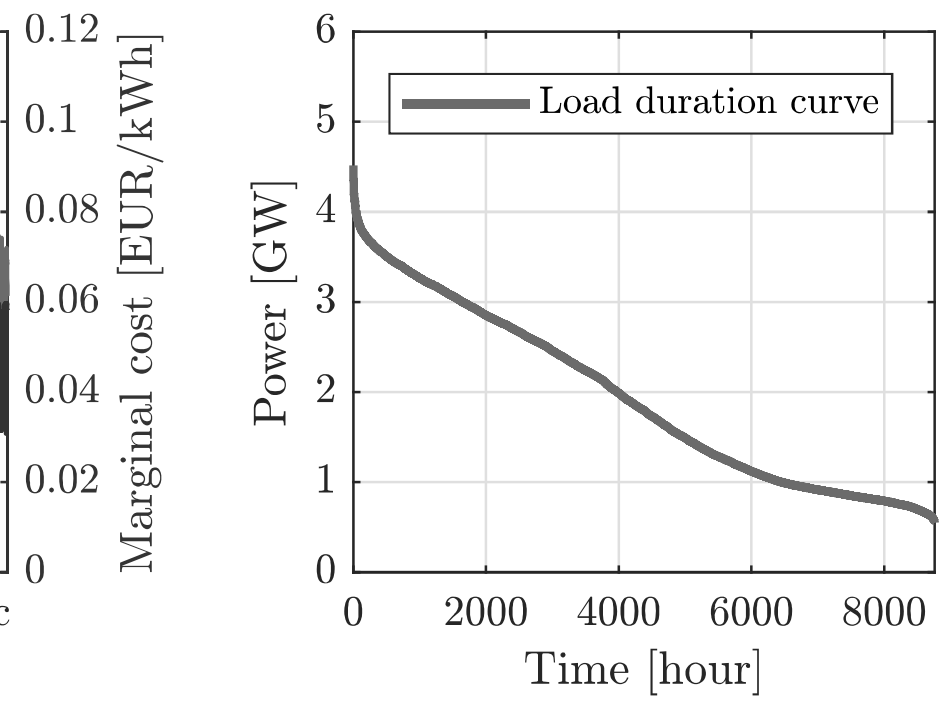

Figure 1: Marginal heat cost and total heating demand for the Greater Copenhagen area $(\sim 2.5$ million inhabitants)

the load peaks, especially on Monday mornings. Since the new generation of buildings has been progressively better insulated, DHW demands will almost be of the same magnitude as the SH demands [20] in these buildings. To give an illustration, hourly measurements of the DH system in Copenhagen's Nordhavn area, a newly constructed residential area with well-insulated buildings, are shown in Figure 2 for the entire 2018: the top plot shows the yearly total DH consumption and that the need for peak shaving is only present in the winter half of the year; the middle plot in Figure 2 shows the first 3 weeks of 2018, from which it can be seen that all workdays marked in blue experience a load peak while non-workdays marked in red does not; the bottom plot contains the demands for every workday during the three weeks and shows that the load peak generally occurs at the same time of the day between 05:00 and 08:00.

\subsection{FCR-N service for power system}

The transmission system operators (TSOs) in regional group Nordic (RG-N) are jointly responsible for procuring $600 \mathrm{MW}$ of FCR-N reserves and each TSO has an allocation proportional to its share of production. Moreover, to maintain system stability, the TSOs of RG-N have a shared set of grid codes which divide primary frequency control (PFC) into two services, namely FCR-N and FCR-D. FCR-N is a symmetrical service, which requires the provider to offer the same power capacity for upwards and downwards regulation. It must be provided linearly according to the frequency deviations from the nominal value without a dead-band, and a full activation must be reached at the deviation of $\pm 100 \mathrm{mHz}$ [21]. While FCR-N is constantly activated, FCR-D is rarely activated only when the system frequency goes below $49.9 \mathrm{~Hz}$. As a result, FCR-N has a significantly higher remuneration.

The power system in Denmark is separated into two parts, which belong to different synchronous zones: western Denmark (DK-1) is a part of the regional group continental 

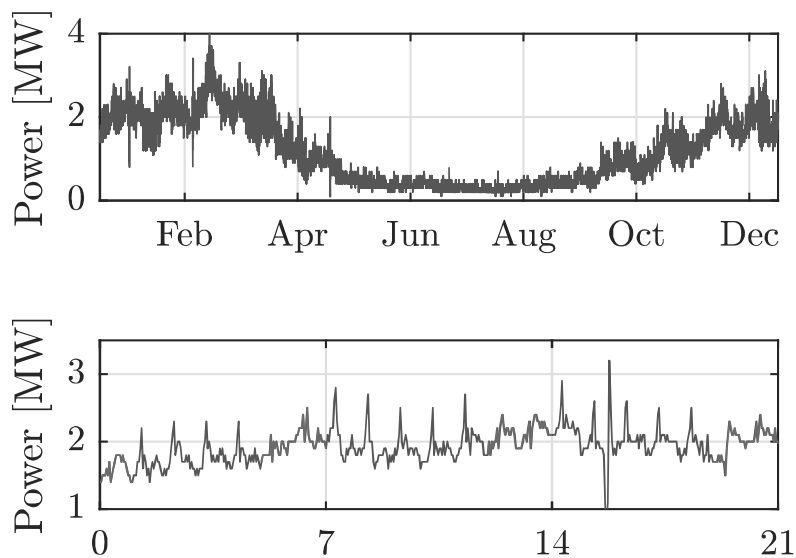

Day of year

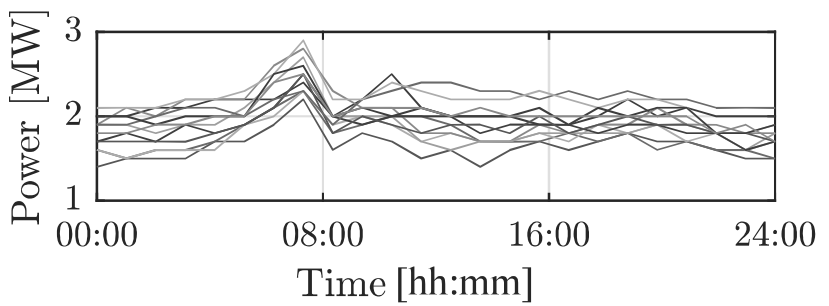

Figure 2: Hourly DH load measurements of the entire Nordhavn area ( 2000 inhabitants $)$ in 2018. Top: Seasonal load pattern. Mid: Weekly loads pattern with non-workdays marked in red. Bottom: Daily load pattern and each line denotes one workday

Europe (RG-CE), and eastern Denmark (DK-2) is a part of the RG-N [22]. Copenhagen's Nordhavn area is the focus of this paper, and it is located in DK-2. Historically, it has been CHPs' role in Denmark to deliver the reserve to maintain the power balance with assistance from hydropower plants in neighbouring countries [23] and keep the system frequency close to its nominal value of $50 \mathrm{~Hz}$. As the electricity production is shifting from the centralised CHP-based production to a distributed intermittent RES-based counterpart, maintaining a balance between the production and the consumption becomes increasingly challenging. Makarov et al. suggest that the fast response of distributed resources can cover the regulation requirements of significantly larger generating units with slower ramp rates [24]. Consequently, the TSO in Denmark has initiated several pilot projects to investigate the reliability of new sources for frequency regulation [22].

Formally speaking, for a frequency value $f_{t}$ at time $t$, the normalised response $y_{t}$ is calculated as Eq. (1).

$$
y_{t}=\left\{\begin{array}{rll}
-1, & \text { if } & f_{t}<49.9 \mathrm{~Hz} \\
\left(f_{t}-50 \mathrm{~Hz}\right) / 0.1 \mathrm{~Hz}, & \text { if } 49.9 \mathrm{~Hz} \leq f_{t} \leq 50.1 \mathrm{~Hz} \\
1, & \text { if } & f_{t}>50.1 \mathrm{~Hz}
\end{array}\right.
$$

To create the symmetry for the unidirectional loads, the power consumed by the service provider at time $t$ needs to be the sum of the response and the base consumption as shown 
in Eq. (2).

$$
P_{t}=P_{\text {cap }} * y_{t}+P_{\text {base }}
$$

Another key thing to remember is that the EHBs involved in the test have discrete power consumption, so the control granularity depends on the number of EHB units. In this study, five EHBs, with $3 \mathrm{~kW}$ each, were aggregated with a total capacity of $15 \mathrm{~kW}$ and the droop curve in Figure 3(a) is discretised with a step of $40 \mathrm{mHz}$ as seen in Figure 3(b). The regulation capacity is in this case $P_{\text {cap }}=7.5 \mathrm{~kW}$.

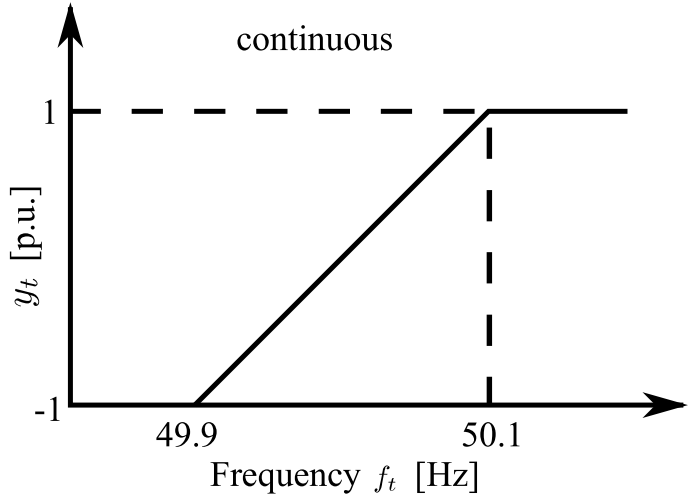

(a)

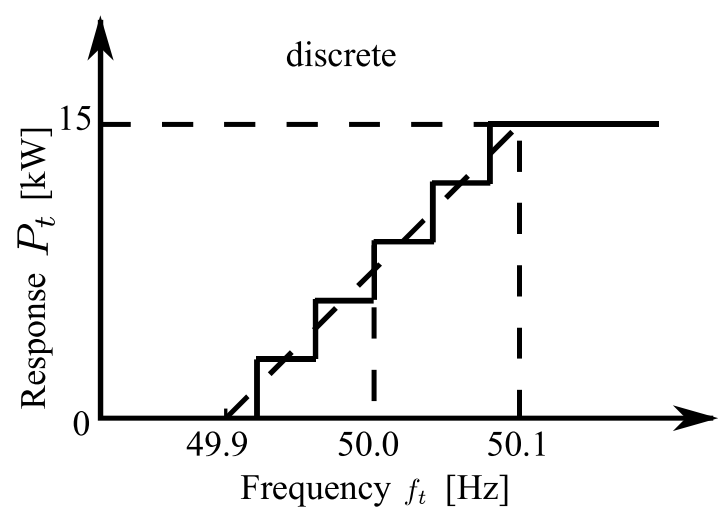

(b)

Figure 3: Droop curve for FCR-N. (a): ideal normalised response; (b): aggregated response

\section{EHB and multi-scale experiment design}

An abstract representation of a single-family building's connection to both the DH network and the low-voltage distribution network is shown in Figure 4. Both systems are coupled by an EHB. The rest of this section presents the multi-scale design which consists

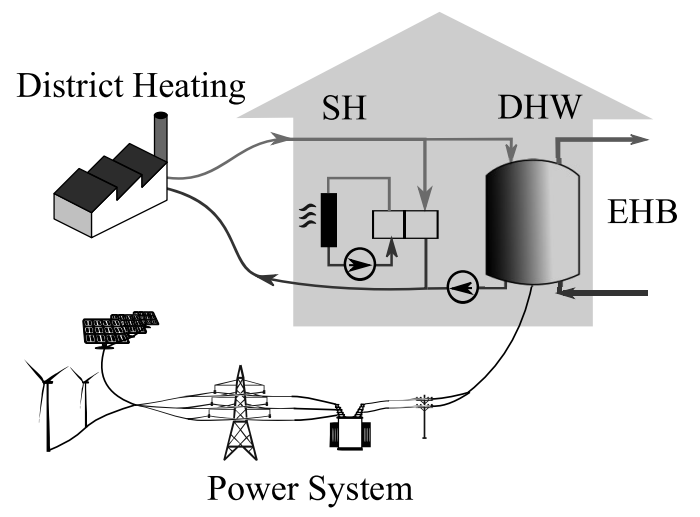

Figure 4: Illustration of residential coupling between DH network and low-voltage distribution network

of three hierarchical levels: level 1 is an augmented DH substation with a standard DH controller; level 2 is a situation-aware control system; and level 3 is an aggregation controller to provide multi-services. 


\subsection{Augmented DH substation: level 1}

Level 1 consists of a standard DH controller, denoted as ECL310, which controls both the SH and DHW of a standard household DH substation. In addition to sensors (S1-6) included in the standard substation, the system is augmented with sensor T1 and T2. A more detailed view of the residential substation configuration is provided in Figure 5, where the DH network into the household has two separate heating circuits. The top heating circuit

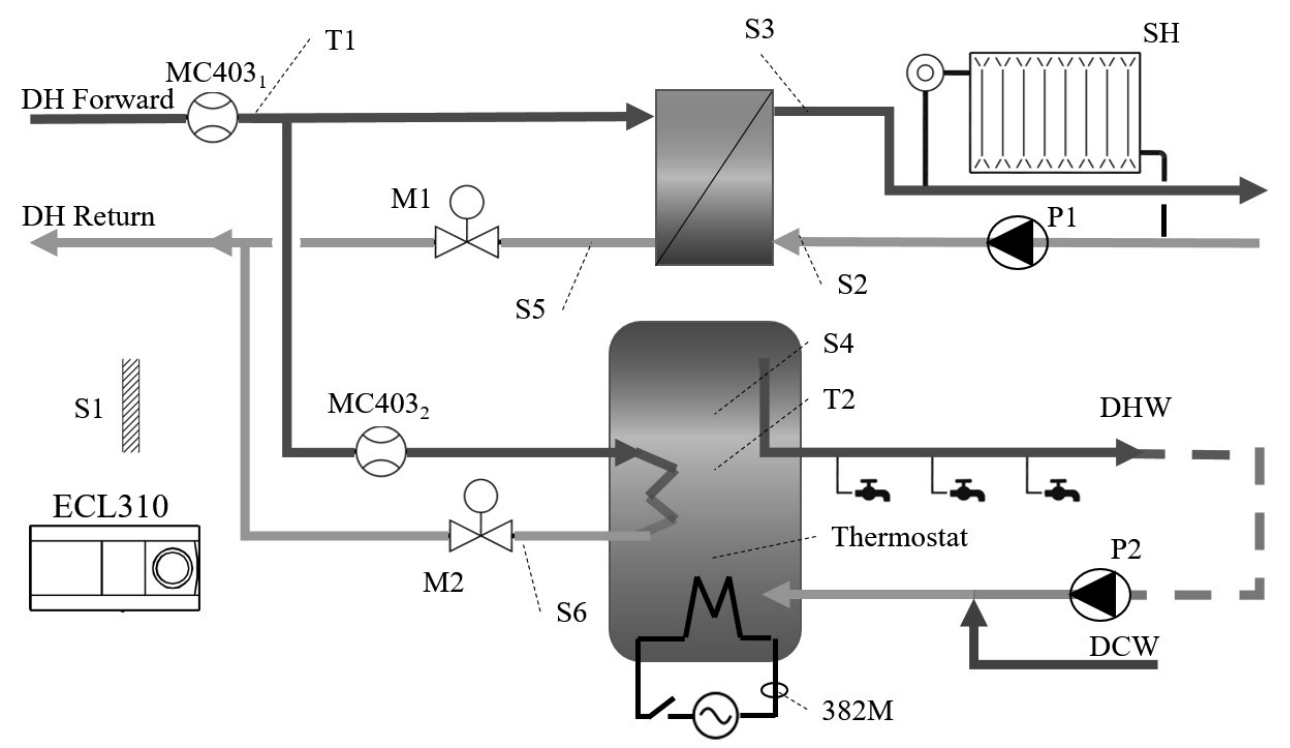

Figure 5: Illustration of augmented DH substation for space heating (the top circuit) and hot water heating (the bottom circuit) [25]

is utilised for SH by controlling the water circulating on the primary and the secondary side of the heat exchanger. The control unit for the substation adapts the temperature setpoint of the forward room heating measurement (S3) based on the outdoor temperature measurement $(\mathrm{S} 1)$ and the user settings such as night setback and occupancy pattern.

The DHW demand for the sinks and showers is supplied by the bottom heating circuit. It is connected with a water tank that can store 92 litres of water, a size designed according to the Danish standard [26]. Apart from the heat exchanger found in a standard substation, a thermostatically controlled electric heating $(\mathrm{EH})$ coil is added inside the tank and is in series connection with an additional relay. This allows enabling/disabling the EH by closing/opening the relay. The main control feedback for ECL310 is S4, and the ECL310 adapts the valve (M2) and pump (P2) to follow a setpoint. The circulation pump P2 maintains a specific water temperature inside the pipes before it is mixed with domestic cold water (DCW) and fed into the bottom of the tank. As part of a standard substation,

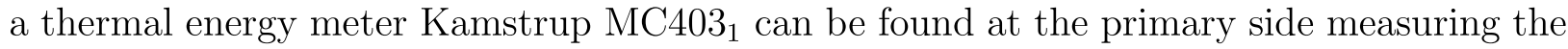
DH energy consumption as well as the forward flow temperature $T_{1}$. In addition to that, a

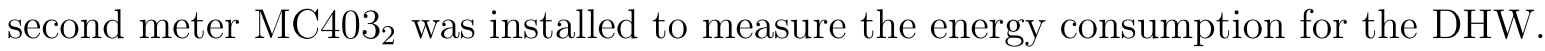

The thermal power from the heat exchanger varies between $3 \mathrm{~kW}$ and $6 \mathrm{~kW}$ depending on the differential pressure, the tank temperature, and the DH supply temperature measured 
as $T_{1}$. Once water is drawn from the tank, cold water of around $10^{\circ} \mathrm{C}$ is fed into the tank. Hence, a full charge cycle to heat 92 litres from $10^{\circ} \mathrm{C}$ to $55^{\circ} \mathrm{C}$ gives an energy capacity of 4.8 $\mathrm{kWh}$, and it was measured to take 48 minutes to heat up. The standby loss is dependent on the difference between the water temperature inside the tank and the ambient temperature. The thermal conductance was measured to be $0.64 \mathrm{~W} /{ }^{\circ} \mathrm{C}$, giving a standby loss of $25.5 \mathrm{~W}$ at the tank temperature of $55^{\circ} \mathrm{C}$ and the ambient temperature of $15^{\circ} \mathrm{C}$.

The $\mathrm{EH}$ is a resistive element with a power rating of $3 \mathrm{~kW}$ at $400 \mathrm{~V}$. The embedded thermostat limits the heating to $65^{\circ} \mathrm{C}$, so heating a cold tank requires $5.3 \mathrm{kWh}$ and a full heating cycle takes 1 hour and 45 minutes using only EH. An electricity meter Kamstrup $382 \mathrm{M}$ with $1 \%$ accuracy for billing purpose was added to measure $\mathrm{EH}$ power consumption. Moreover, since EH can only be switched on or off, the electric power is either $0 \mathrm{~kW}$ or 3 $\mathrm{kW}$. The key parameters for the EHB are summarised in Table 1.

\begin{tabular}{ccc}
\hline Parameter & Value & Unit \\
\hline Water volume & 92 & litre \\
DH rating & $3 \sim 6$ & $\mathrm{~kW}$ \\
EL rating & 3 & $\mathrm{~kW}$ \\
Energy capacity & $4.8 \sim 5.3$ & $\mathrm{kWh}$ \\
Thermal conductance & 0.64 & $\mathrm{~W} /{ }^{\circ} \mathrm{C}$ \\
\hline
\end{tabular}

Table 1: Summary of key EHB parameters

\subsection{EHB situation-aware controller: level 2}

The level 2 controller, also denoted as the FS controller, was designed to be situationaware [27] and built with a fall-back functionality. That is to say, it can react to changing environmental conditions and guarantee that the end-user demand is satisfied during the operation. The controller can be in one of three states: LTDH state which means the DH system operates at low supply temperature and there is a need for temperature boosting; hot temperature $\mathrm{DH}(\mathrm{hDH})$ state which uses $\mathrm{DH}$ as the energy source; and $\mathrm{EH}$ state which uses electricity as the energy source. More details of the three states can be found in the Appendix. The condition of the local DH network is first estimated based on the supply temperature of $T_{1}$. If the supply temperature $T_{1}$ is more than $60^{\circ} \mathrm{C}$, the network is considered to be hot $\mathrm{DH}$ and the controller runs in normal operation mode with the valve M2 automatically controlled and the relay disconnecting the $\mathrm{EH}$, whereas $T_{1}<60^{\circ} \mathrm{C}$ is considered as LTDH. It is not sufficient to avoid Legionella contamination and needs temperature boosting using electricity. The level 2 controller then ensures that EH and DH are not used at the same time and that the consumers have sufficient DHW. The details of conditions for state transitions are also explained in the Appendix in detail.

The Java-based level 2 controller was running on a Raspberry Pi that was placed in the single-family building and can function both autonomously based on the local measurements such as DH supply temperature level and receive an external FS command [25]. The implementation at the building level is further illustrated in Figure 6. The controller in level 1 


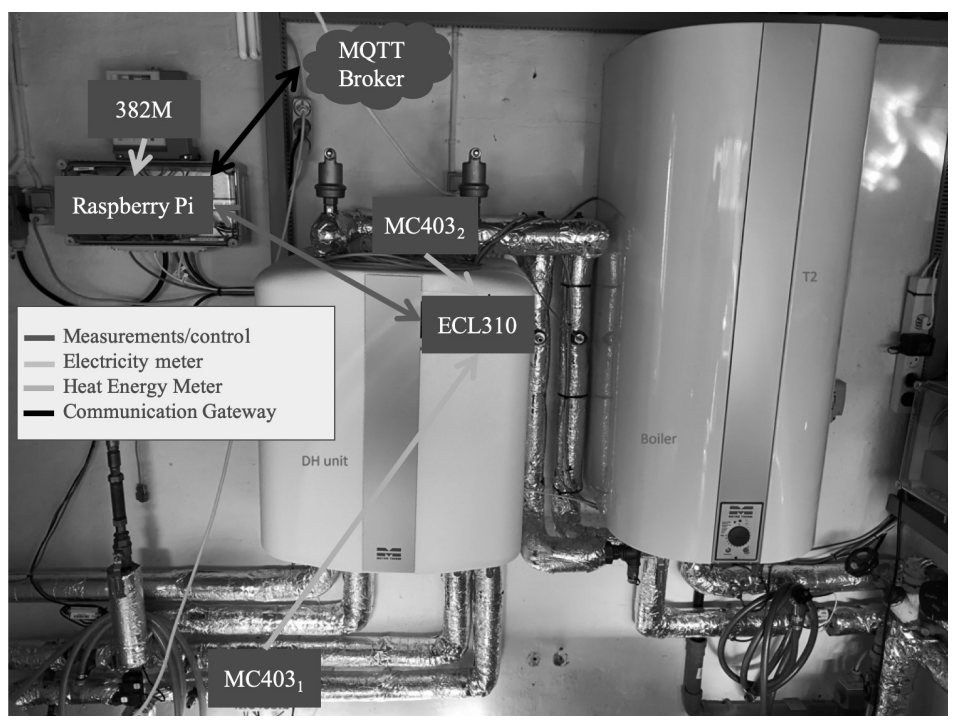

Figure 6: Situation-aware controller as part of an EHB in level 2 [25]

collects the measurements from all the sensors and make these measurements available for the controller in level 2 via the Modbus-TCP interface.

\subsection{Multi-service controller: level 3}

The level 3 controller, denoted as the multi-service controller, aggregates the distributed EHBs using the FS control interface provided in level 2. The only signal sent from the level 3 controller to the level 2 controllers is the FS signal. Since each building is equipped with one level 1 controller and one level 2 controller, there are multiple level 1 and level 2 controllers, whereas there is only one level 3 controller. The overall communication and control architecture is illustrated in Figure 7, where the grey area shows the system under the test. It concerns the electric power, DH, information and communications technology (ICT) and control domains. We separate ICT and control domain to acknowledge the fact that devices such as the meters are read-only, whereas the controllers at level 1 and 2 provide control interfaces for the controllers in upper levels. The communication infrastructure uses the message queuing telemetry transport (MQTT) protocol [29], which adopts a publish/subscribe pattern. The lightweight protocol designed for embedded systems with limited computing power and memory has a broad application in smart sensors, mobile devices and virtual power plant [30].

In all the tests, a dedicated virtual private network was created to secure the communication. The EHBs were placed in Nordhavn, while the MQTT broker was located in Ris $\varnothing$, $30 \mathrm{~km}$ from the EHBs. The communication was over a wireless $3 \mathrm{G}$ network and the wide spatial distribution of the EHBs and MQTT rises concerns over communication delays that might affect the FCR-N provision. Hence, the round-trip communication delays were identified and summarised in Figure 8. It shows a clear daily and weekly patterns with high delays during the working hours. The maximum delay of $200 \mathrm{~ms}$ is not critical for FCR-N, which requires a full response within 150 seconds. 


\section{Results}

This section presents the findings of the research, focusing on two key themes that the design of EHB supports LTDH and an IDR program. Four test cases were developed and summarised in Table 2. It gives an overview and a comparison of the different test cases in terms of the number of units involved, the energy source(s) and the service(s) provision. They are elaborated in the rest of the section. Note that more details about the modelling and control can be found in our previous work [11] and are left out for simplification. While section 4.1 describes a test in the laboratory with a $\mathrm{DH}$ emulator, section 4.2, 4.3 and 4.4 show the tests in the real urban energy system of Nordhavn in Copenhagen.

\section{1. $L T D H$}

At the time of experiments, the LTDH is not yet realised in the Nordhavn area, since it is part of a city-scale DH network and the rest of the network is not yet ready for LTDH. Nonetheless, EHB's capability of supporting LTDH is validated with the help of a LTDH emulator [25] at a low supply temperature of $55^{\circ} \mathrm{C}$ in a laboratory environment. In addition 


\begin{tabular}{cccc}
\hline Test cases & Nr. of Units & Energy source(s) & Service(s) provision \\
\hline LTDH & 1 & DH \& EL & LTDH \\
Base case & 5 & DH & N/A \\
Peak shaving & 5 & DH \& EL & Peak shaving \\
Multi-service & 5 & DH \& EL & Peak shaving \& FCR-N \\
\hline
\end{tabular}

Table 2: An overview of different test cases

to that, a water tapping pattern taken from the Danish national standard [26] was applied to examine the sufficiency of hot water supply. The results of this test are shown in Figure 9. The top plot shows the temperature measurements at two heights of the tank used to
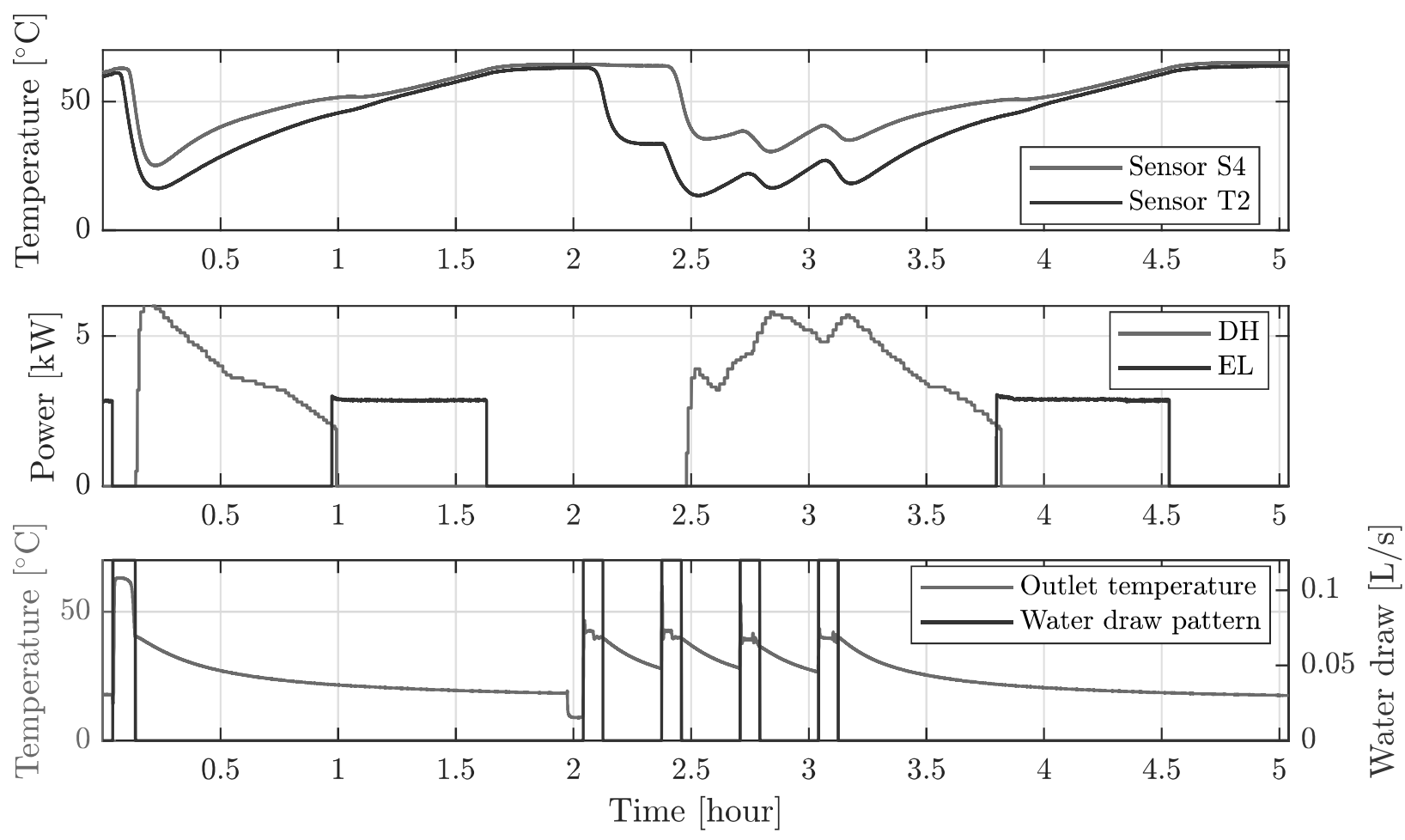

Figure 9: Verification of EHB design under LTDH with a supply temperature of $55^{\circ} \mathrm{C}$

indicate the stratification inside the tank. The sensor S4 was used as a feedback in the level 1 controller, while sensor T2 was used in the level 2 controller. The middle plot shows the energy usage of $5.6 \mathrm{kWh}$ from the DH system and $2.1 \mathrm{kWh}$ from the electrical system, giving $72.7 \%$ and $27.3 \%$ of energy source composition from DH and electricity. Furthermore, it can be observed that energy was first drawn from $\mathrm{DH}$ system followed by boosting using electricity. The top plot shows the turning point was when sensor T2 reaches $45^{\circ} \mathrm{C}$, as the state machine design in the Appendix.. The four water draws shown in the bottom plot of Figure 9 are of 5 minutes each, with a total draw of 57 litres of mixed tap water at between $40^{\circ} \mathrm{C}$ and $45^{\circ} \mathrm{C}$. The mixed water at the tap is shown to be always above $40^{\circ} \mathrm{C}$ in the same 
plot and thus validates that the design complies with the national standard. The rest of the section examines a IDR program by aggregating five single-family houses.

\subsection{Base case}

Section 4.2, 4.3 and 4.4 describe the tests carried out in Copenhagen's Nordhavn district, whose DH network is illustrated in Figure 10.

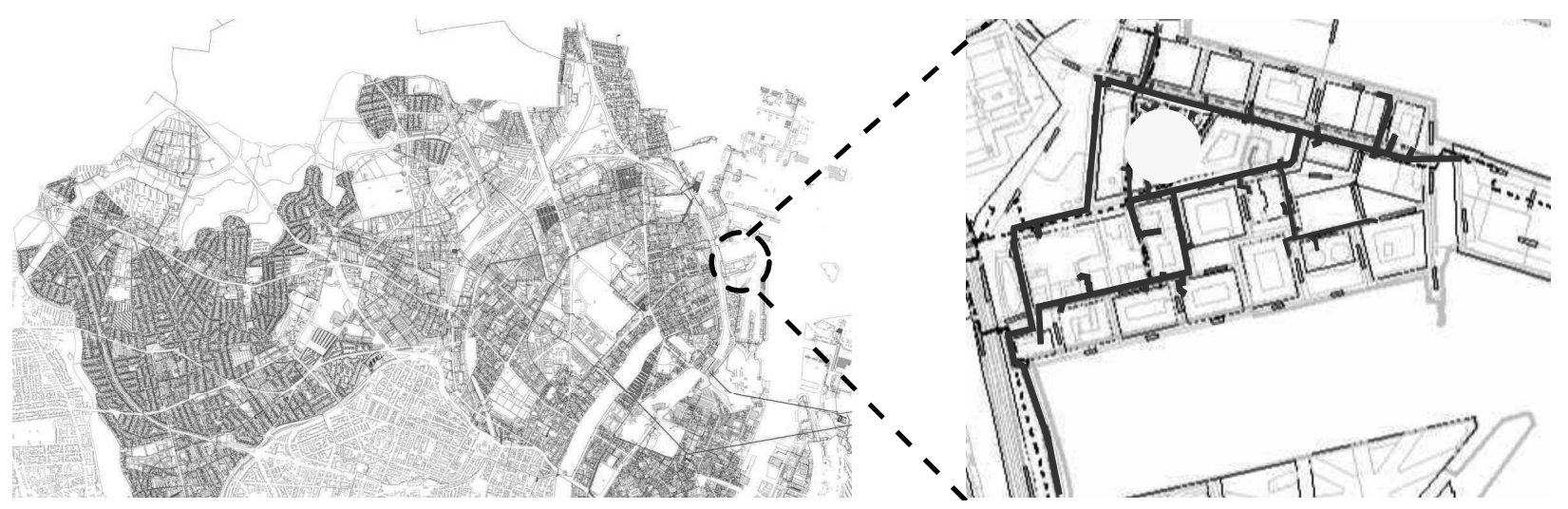

Figure 10: Buildings (yellow dot) involved in the demonstration are connected to the Nordhavn DHN (right), which is a part of a city-scale DHN (left) in Copenhagen [31]

Before presenting the results from the IDR program, a base case was carried out to provide the reference for comparison in the rest of the paper. In the base case, the EHB uses DH as the only energy source, and DH operates as the standard substation. The measurements during five working days are summarised in Figure 11, where the combined DH consumption of the five single-family houses is shown with one line for each day.

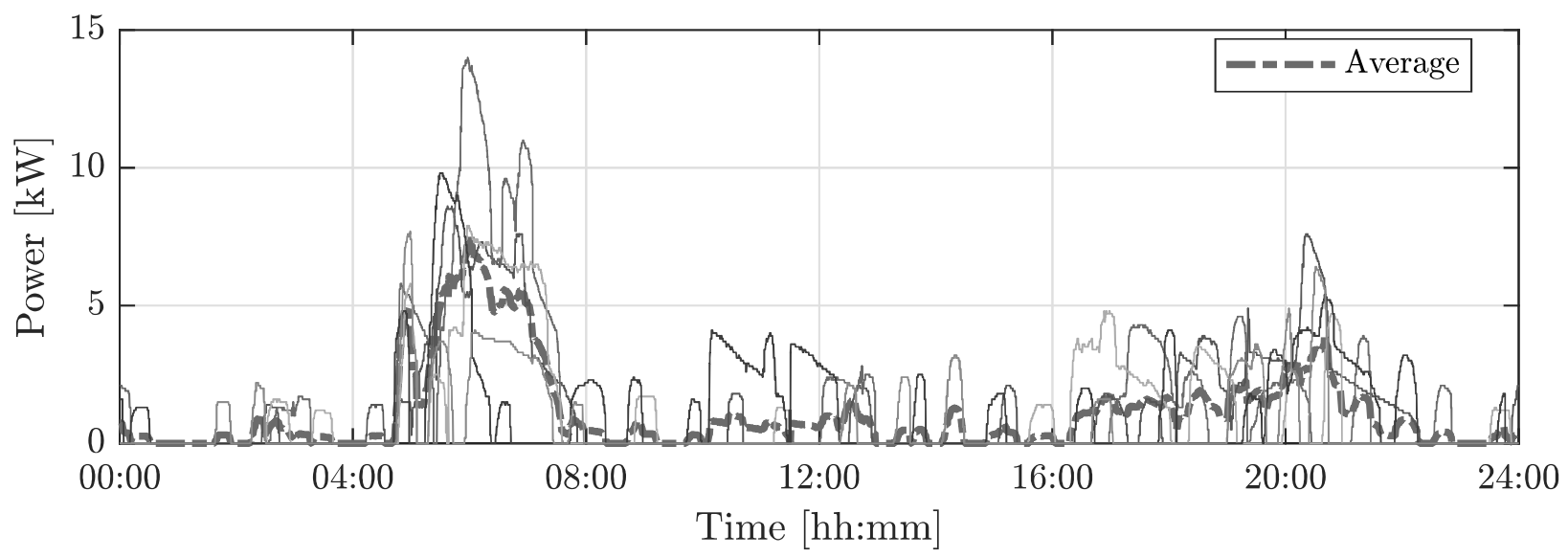

Figure 11: Red dashed line shows the average aggregated DH power from the five EHBs. For the solid lines, each colour denotes the daily aggregated EHBs DH power for one working day - base case

Although the consumption pattern is tightly related to end-user behaviour, the average total DH power for the five EHBs, as shown in Figure 11, implies large water draw and 
energy consumption between 04:00 and 08:00 and more spread consumption in the evening. The morning peak overlaps with the peak of all of Copenhagen shown in Figure 2. The average peak power and energy that can be shifted during between 04:00 and 08:00 are $7.5 \mathrm{~kW}$ and $13 \mathrm{kWh}$. The average daily energy consumption per EHB is estimated to be $5.4 \mathrm{kWh}$. To estimate end-user comfort levels, distribution of temperature measurements of all the EHBs is presented in a bar chart in Figure 12.

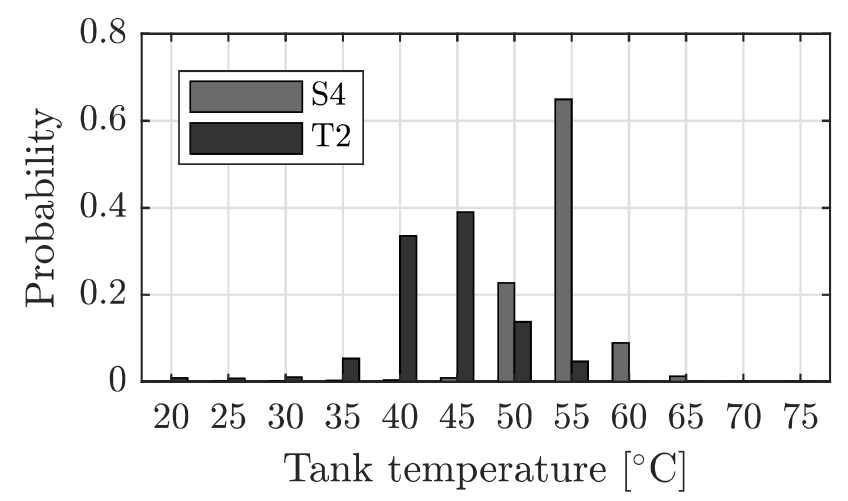

Figure 12: Temperature distribution for all houses - base case

It shows that $98.9 \%$ of the time, sensor $\mathrm{S} 4$ measurements were over $45^{\circ} \mathrm{C}$ and the temperatures centred around $55^{\circ} \mathrm{C}$ which is the set point of $\mathrm{DH}$ substation. In the analysis, we defined the comfort level as the cumulative probability of S4 temperature above $45^{\circ} \mathrm{C}$, higher than the level required by the Danish standard [26]. Hence, results in Figure 12 imply a comfort level of $98.9 \%$.

\subsection{Peak shaving service}

This section provides test results when the five EHBs were aggregated to deliver a peak shaving service to the DH system. Daily peak hours were forecast one day ahead through statistical analysis of the total power measurements from the past three months. During the peak hours, the level 3 controller broadcasts FS signals to all the electric heat boosters, which switch to electricity as their energy source. The experiment carried out in the week 11 of 2019 is summarised in Figure 13 showing the aggregate DH power of the 5 EHBs for each of the 5 workdays and the average of the 5 workdays. It can be observed that morning peaks shown in the reference case in Figure 11 were completely removed. On average, 2.1 $\mathrm{kWh}$ of DH energy and $4.3 \mathrm{kWh}$ of electricity were used per day per EHB.

A distribution of temperature measurements of all the EHBs is presented in a bar chart in Figure 14, which shows that $99.2 \%$ of the time, sensor S4 measurements were over $45^{\circ} \mathrm{C}$ and the temperatures were distributed between $55^{\circ} \mathrm{C}$ and $70^{\circ} \mathrm{C}$. This result implies a comfort level of $99.2 \%$. Hence, we can conclude that the comfort level was slightly increased when providing peak shaving services. Compared with the reference case, $1 \mathrm{kWh}$ more energy was used. This can be attributed to the variation in the water usage pattern. 


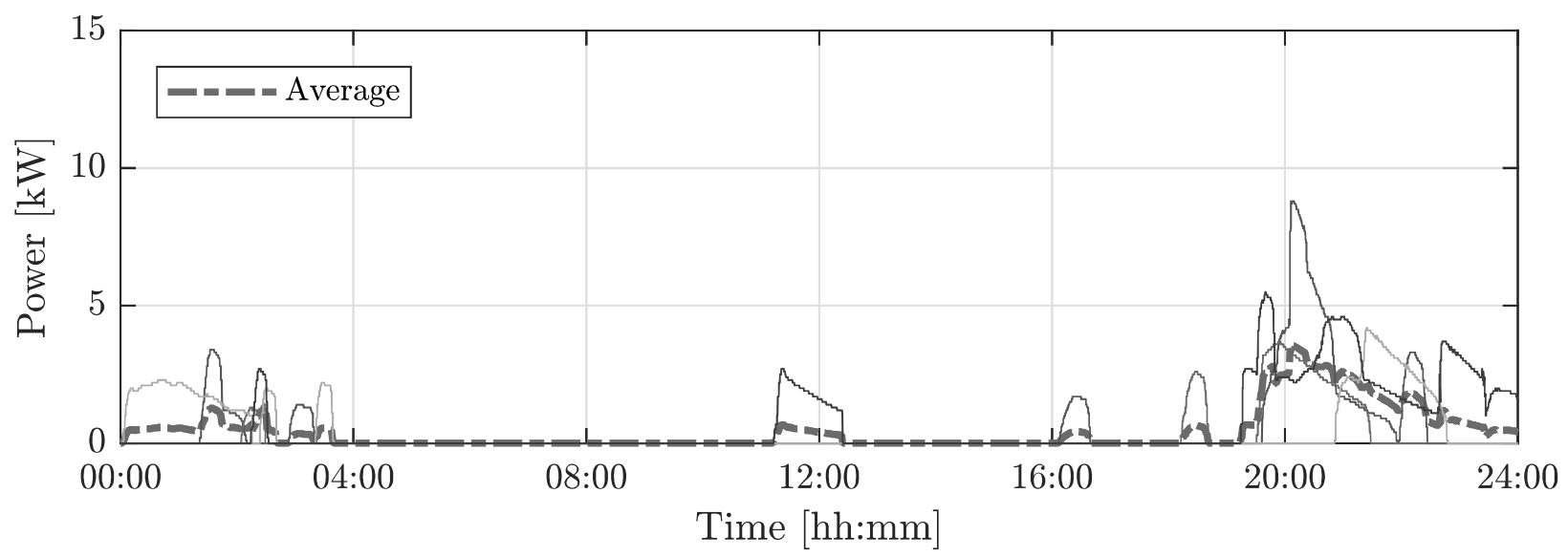

Figure 13: Red dashed line shows the average aggregated DH power from the five EHBs. For the solid lines, each colour denotes the daily aggregated EHBs DH power for one working day - peak shaving

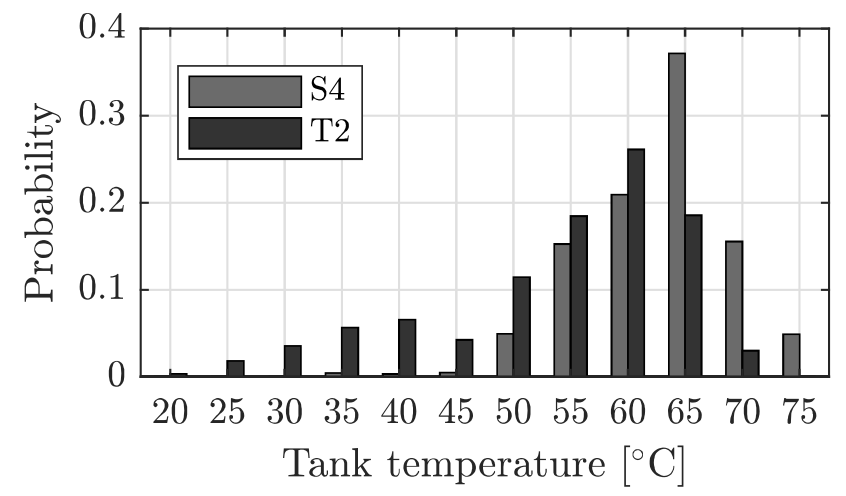

Figure 14: Temperature distribution for all houses - peak shaving 


\subsection{Peak shaving and FCR-N services}

This section presents the experimental results when combining the peak shaving service provision to the DH system and the FCR-N service provision to the power system. During the period of requested FCR-N service, the level 3 controller calculates a desired electric power response according to Figure 3 and frequency measurements. The level 3 controller sends FS signals to EHBs, whose combined electric power matches the desired electric power response as much as possible. EHBs were selected based on tank temperature and tanks with lower temperature were given higher priority to be selected.

The frequency measurements during the morning peak hours are shown in the top plot in Figure 15 and the bottom plot shows both the ideal and the real aggregate electric power while providing FCR-N. The measured aggregate electric power has the same shape as
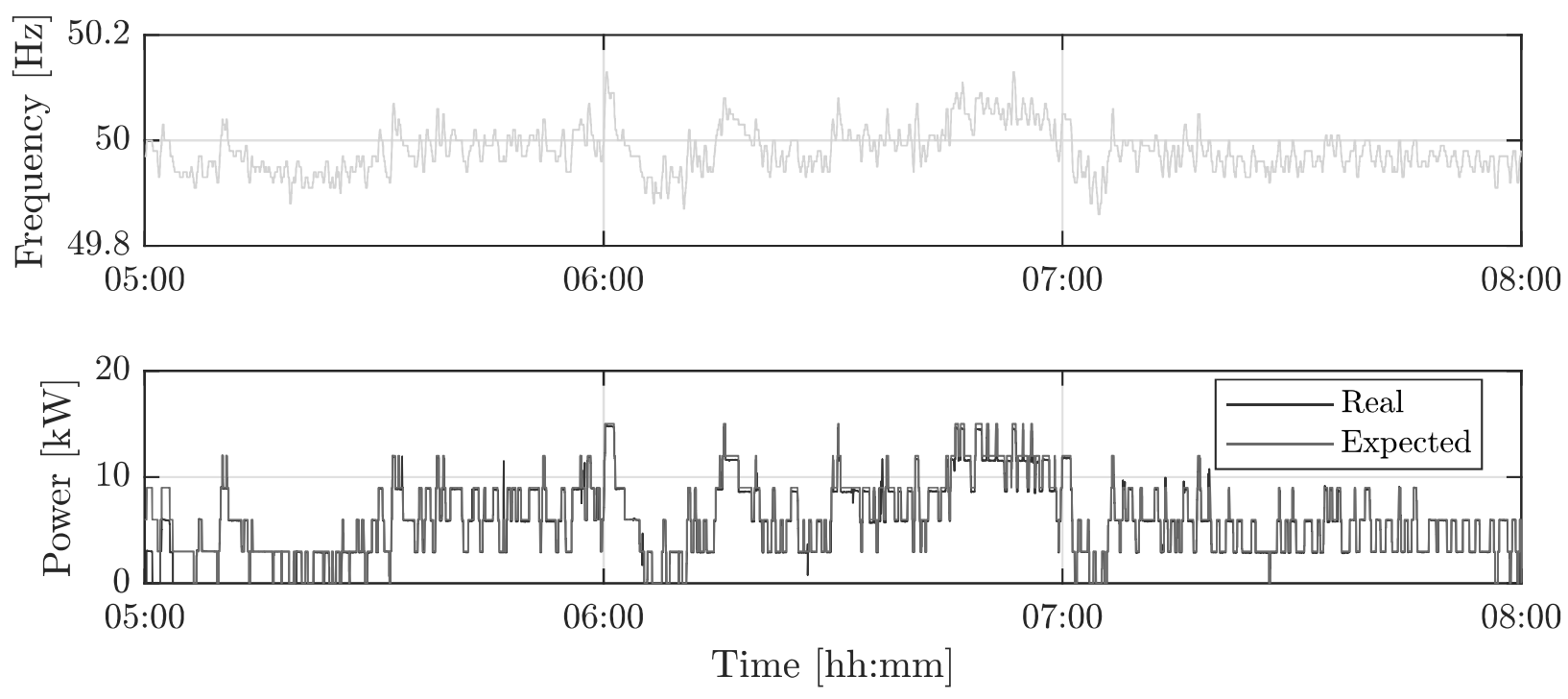

Figure 15: Primary frequency control result: time-series view

the ideal response seen in Figure 3 (b), although there are visible lags in time. The time delays are attributed to the delays in communication, actuation and unsynchronised meters. Furthermore, the mismatches observed from Figure 15 can be attributed to communication loss, voltage variation or insufficient capacity for energy intake. To identify the activation time, a basic statistical analysis approach was taken by examining the correlation between the frequency deviations and the aggregated electric power. The analysis is summarised in Figure 16, which shows the correlation level with respect to the activation time. It can be observed that the maximum correlation occurs at an activation time of 4 seconds. The pairs of frequency and aggregated electric power is shown in the scatter plot in Figure 17 along with the expected response. It can be observed that the real response follows the expected response, although outliers exist. This shows that the aggregation of the EHBs satisfies Energinet's FCR-N requirement, which asks for a full activation within 150 seconds [21]. As EHBs can not modulate the power consumption themselves, they need to be aggregated together as a group in order to give the correct response relative to the frequency deviation. 


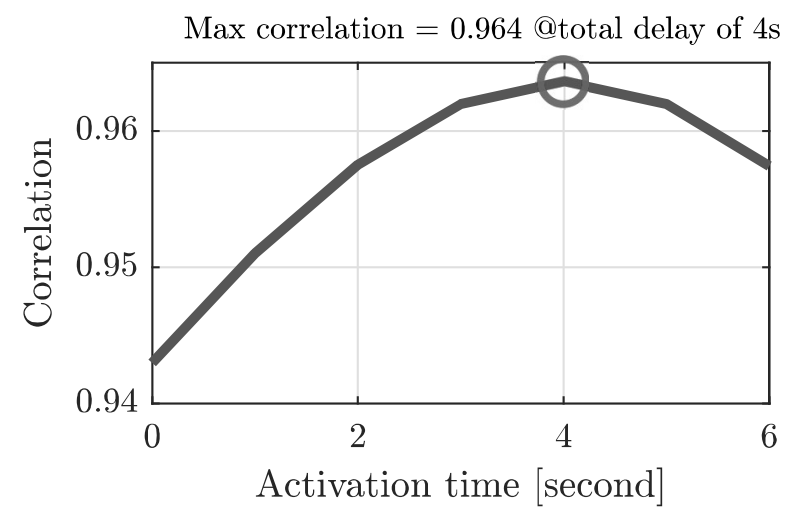

Figure 16: Analysis of the correlation between frequency measurements and aggregated EL power

However, it is also necessary to reach the minimum bid size of $0.3 \mathrm{MW}$, which requires 200 EHBs or use EHBs in a combination of other types of units. When the number of EHBs increases, the response that is shown in Figure 17 will become more linear.

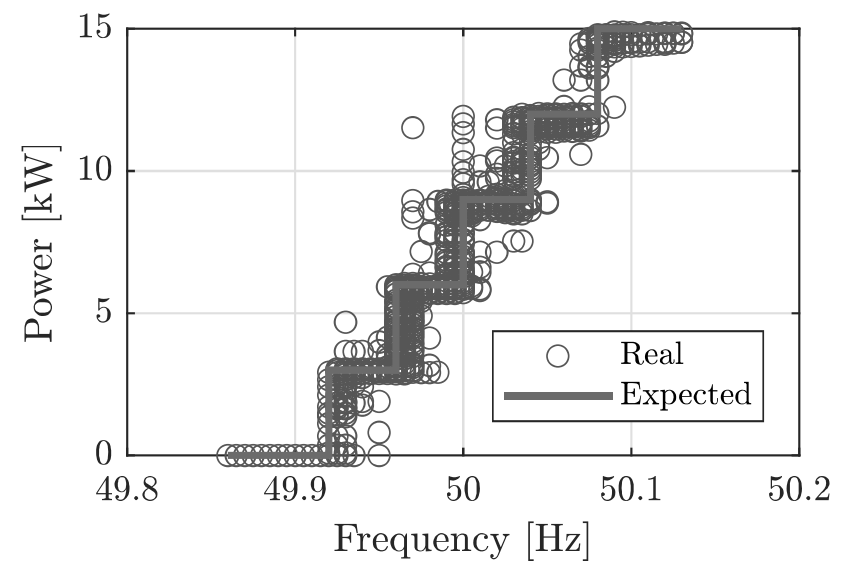

Figure 17: Comparison of the real aggregate response with the ideal response

At the same time, a peak shaving service was also provided. Its performance can be seen in Figure 18. It can be observed that DH power consumption during peak hours was substantially reduced compared with the reference case in Figure 11. However, the peak was not totally removed as in the peak shaving case in Figure 13. The reason is that there were under frequency events during the peak hours, which require few EHBs to be used. In order to guarantee end-users' comfort, DH power was still used in the case when the electrical heating was disabled, and tank temperature was low. The FCR-N service was prioritised over the peak shaving service to the DH system because the DH system has larger inertia than the power system. To put it another way, a conflict arose when both services were acquired and it was resolved by giving priority to the service for electrical system which has faster dynamics.

Moreover, Figure 19 summarises the distribution of temperature measurements of all the EHBs. It can be observed that $98.9 \%$ of the time, sensor S4 measurements were over $45^{\circ} \mathrm{C}$ 


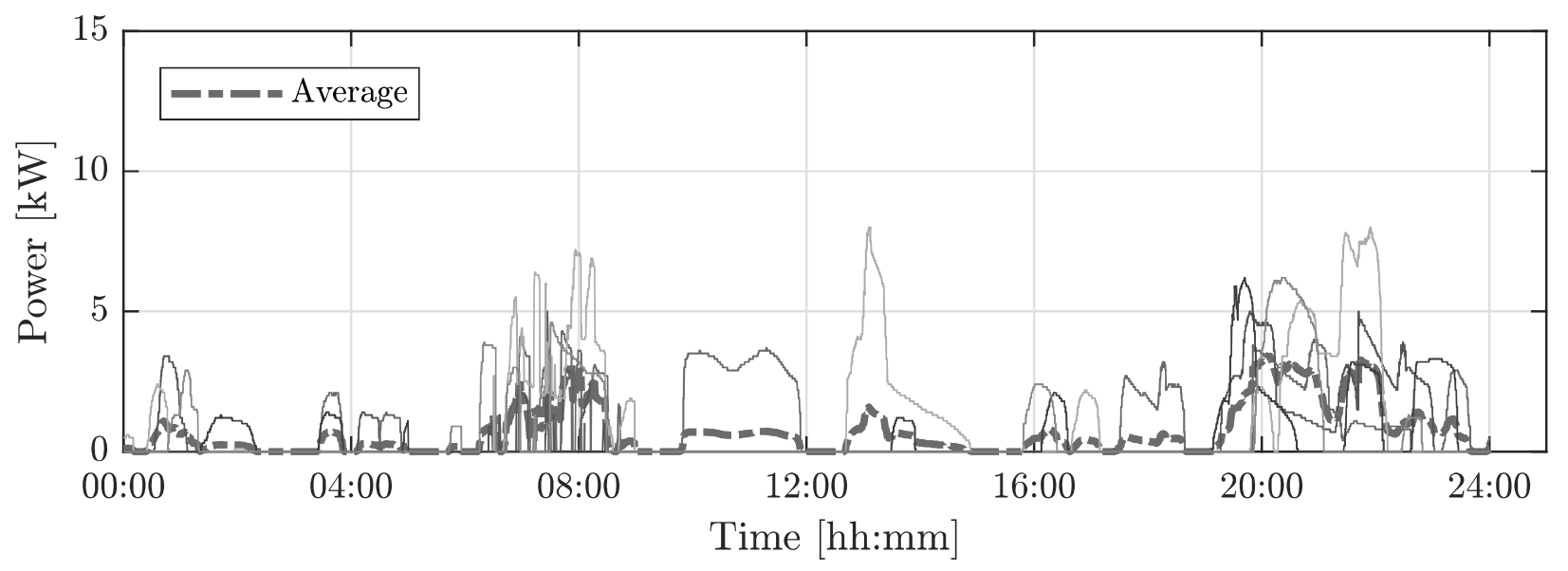

Figure 18: Red dashed line shows the average aggregated DH power from the five EHBs. For the solid lines, each colour denotes the daily aggregated EHBs DH power for one working day - multiple services

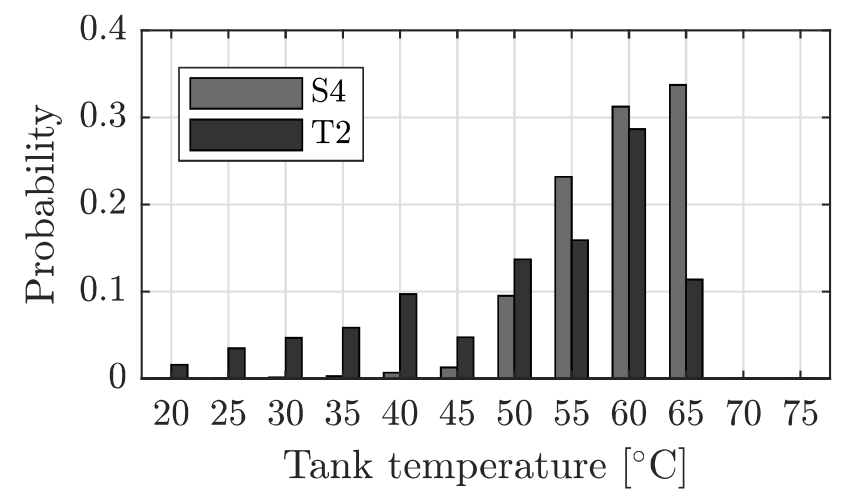

Figure 19: Temperature distribution for all houses - multi services 
and the temperatures were more widely distributed between $50^{\circ} \mathrm{C}$ and $65^{\circ} \mathrm{C}$. This implies a comfort level of $98.9 \%$ and confirms that end users' comfort was maintained during the test. On average, $3.3 \mathrm{kWh}$ of DH energy and $2.8 \mathrm{kWh}$ of electricity were used per day per EHB.

The switching actions of the relay illustrated in Figure 5 are summarised in Table 3 along with the specification of an off-the-shelf relay. In the tests, the operating rates were measured to be between 16 and 24 cycles/hour. Hence, electrical durability of $5 \times 10^{5}$ cycles gives an estimated life expectancy of $2.3 \times 10^{4}$ hours while providing FCR-N service.

\begin{tabular}{ccc}
\hline Parameter & Value & Unit \\
\hline Meas. operating rate & $16 \sim 24$ & cycles/hour \\
Max. operating rate & 3600 & cycles/hour \\
Mechanical durability & $10^{7}$ & cycles \\
Electrical durability & $5 \times 10^{5}$ & cycles \\
Est. life expectancy & $2.3 \times 10^{4}$ & hours \\
\hline
\end{tabular}

Table 3: Relay specification and measured relay switch actions

\subsection{Economic assessment}

In this section, the economic aspects of both the peak shaving service in the DH system and the frequency response service in the power system are explained. We first explain why the peak shaving service is not visible in the existing DH market, followed by the potential remuneration options. Then we evaluate the frequency response revenues according to historical price data from the reserve market.

Copenhagen's heat market, Varmelast.dk, has been responsible for thermal load distribution in the Greater Copenhagen area [32] since 2008. In current market design, heat producers submit bids to the market two days ahead, and bids with the lowest marginal cost are provisionally accepted. Load distribution is revised iteratively until all hydraulic constraints are satisfied. In this market design, only day ahead marginal heat cost is visible. Aggregating loads to reduce peak and address network hydraulic constraint is not yet a service that could be traded on existing market. Nonetheless, the experimental demonstration and associated technical and economic evaluation presented in this study provide DH system operators with insights into this new tool.

Potential ways to remunerate a peak shaving service are suggested here. Firstly, a peak shaving service, aggregating a sufficiently large amount of EHBs can allow CHP owners to dispatch more flexibly in the heat market and enhance energy arbitrage capabilities in the Nordpool electricity market, as the current heat market clearing precedes the Nordpool market. Part of the gains from improved energy arbitrage can be used to remunerate the participants to establish a sustainable business. Secondly, the peak shaving service improves the DH network operation and quality of service. It also helps to address the congestion that exists in the network [33], instead of increasing network dimension or operating at a high marginal heat production cost. This saving can be turned into remuneration for the 
service provider. The exact value of the revenue in these two cases requires a social-economic analysis and is not calculated in this paper. The experimental demonstration presented in this study provides insights for the decision-makers into new tools for improving the quality of service and operation.

At the same time, the FCR-N reserve is, according to current market set up, paid per available power capacity, $P_{\text {cap }}$, for the contracted period, independent of the number of activations. The price is settled day ahead in an open market and varies depending on the supply. As stated earlier, the delivery period for the FCR-N service is preferably desired to be overlapped with the need for peak shaving. From Figure 2, it is shown that peak shaving needs only occur in the winter months and it is most often three hours between 05:00 and 08:00. The average availability payment of those specific hours during the last 4, 5 years (2015-2019) is $33 \mathrm{EUR} / \mathrm{MW}$-h, which means being available to provide FCR-N with one MW and for one full hour will be remunerated with 33 EURs [7]. Aggregating the five EHBs to a reference consumption of $7.5 \mathrm{~kW}$ and to stay available with $\pm 7.5 \mathrm{~kW}$ gives a capacity of $\pm 1.5 \mathrm{~kW}$ per EHB. Thus, three hours of regulation gives a capacity payment equal to $\pm 1.5 \mathrm{~kW} \times 0.033 \mathrm{EUR} / \mathrm{kW}-\mathrm{h} \times 3$ hours $=0.15 \mathrm{EUR} /$ day. Assuming that the service is delivered every workday in the heating season, 125 workdays results in $19 \mathrm{EUR} /$ year. The service could be delivered every day, to give a higher revenue of $54 \mathrm{EUR} /$ year in comparison to $52 \mathrm{EUR} /$ year for 3 hours of frequency regulation per day from an EV with unidirectional charging.

\subsection{Comparison of three cases}

The share of energy sources for the three cases is visualised in Figure 20. It can be observed that the base case has the lowest energy consumption, whereas the peak shaving case consumes the most with also the highest share of electricity usage. However, differences in the overall energy consumption can only be caused by variations in the user behaviour as the effect of a higher temperature in the tank on the convection losses is insignificant. Besides, there is a sizable difference between electricity and DH price for private customers in Denmark. Typical electricity price after the tax deduction is $0.31 \mathrm{EUR} / \mathrm{kWh}$, whereas the DH price is $0.09 \mathrm{EUR} / \mathrm{kWh}$. Daily energy costs were $0.47 \mathrm{EUR}, 1.51 \mathrm{EUR}$ and 1.17 EUR for base case, peak shaving case and multi-service case respectively.

A spider plot comparing all three cases is presented in Figure 21 with respect to the total daily energy usage, performance of peak shaving service (DH peak shaving benefits), revenue from FCR-N provision for power system (Revenue EL), revenue for supporting LTDH (LTDH benefits), substation cost (Hardware cost) and comfort level. Note that hardware cost consists of the cost of conventional district heating substation, additional energy meter and micro-controller.

From Figure 21, it can be seen that the base case has the lowest energy consumption and the lowest hardware cost. The peak shaving case brings the most revenue from the peak shaving service. The multi-service design generates the most benefits from providing FCR-N, supporting LTDH and satisfying the end-user demand. The revenue for peak shaving and supporting LTDH can not be directly quantified from the existing market; it is instead presented as a performance indicator of the service provision in percentage. 


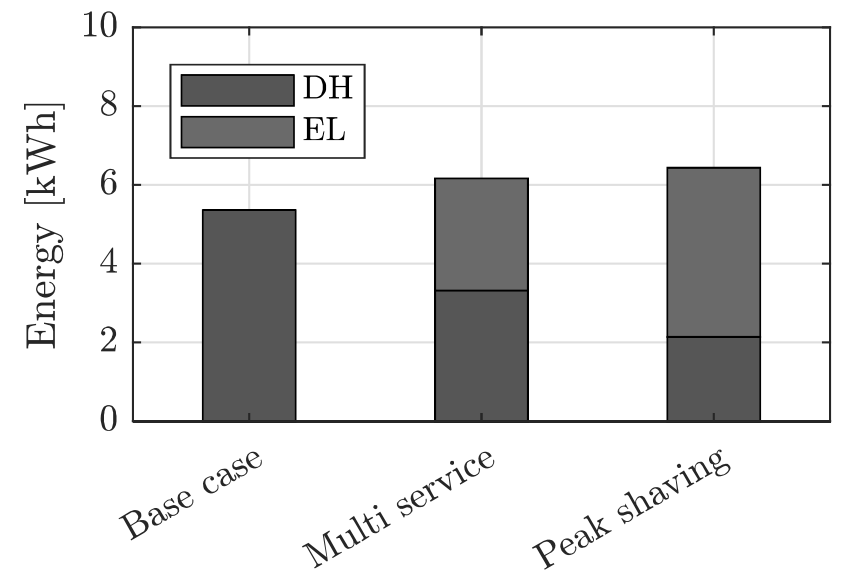

Figure 20: Comparison of the share of energy source in all cases

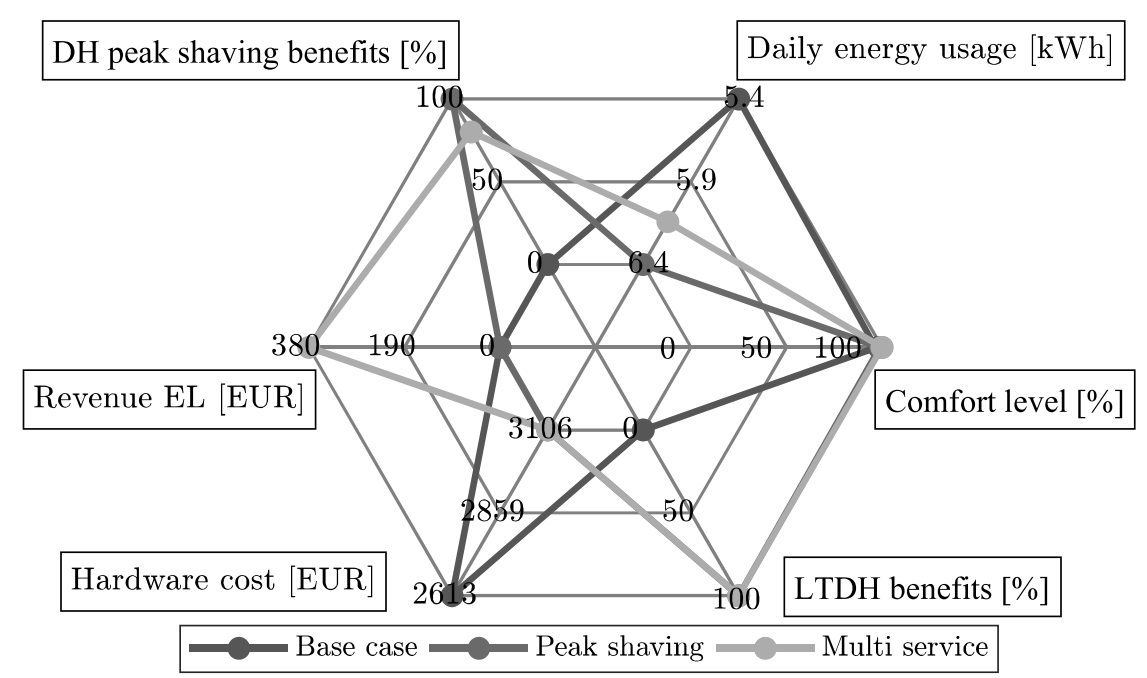

Figure 21: Comparison among three test cases with respect to six key criteria 


\section{Conclusion}

This study examines the emerging role of the integrated demand response (IDR) in the context of integrated electricity and district heating (DH) system. Design of the electric heat booster (EHB) that couples both systems was proposed. It has both energy sources available for the water heating demand. The overall control was structured into three levels: (i) augmented commercial DH substations; (ii) distributed situation-aware control systems; and (iii) an aggregation controller. Four test cases were devised to evaluate the proposed design of EHB in supporting low-temperature district heating (LTDH) and a IDR program. The results show that frequency-controlled normal operation reserve (FCR-N) can be delivered with an activation time of four seconds while providing significant load reduction to the DH network during peak hours. It was also verified that the end-user comfort was maintained in all cases. Overall, these results provide valuable insights into the technical aspects and the economic outlook for IDR.

The findings in this paper are limited due to the fact that the end-user energy consumption pattern may be specific to the local community. Further research and demonstration programs are needed to investigate the tests on a larger scale to achieve an impact visible at the system level. Although this paper demonstrates only two services to illustrate a IDR program, the developed platform is not restricted to these two services, and future work includes investigating a combination with other types of services to enhance the economic outlook.

\section{Appendix}

This appendix explains the state machine implemented in level 2 controller in detail.

\section{Hot DH state}

When the supply temperature $T_{1}$ is higher than $60{ }^{\circ} \mathrm{C}$ it implies the $\mathrm{DH}$ system is operating on conventional temperature level and it is high enough to avoid Legionella contamination. Hence, the level 1 controller adjusts the M2 valve automatically with the electric coil disconnected. In this state, only DH is used as the energy source for water heating. The state transits if:

- $T_{1}<60^{\circ} \mathrm{C}$, state $\rightarrow \mathrm{LTDH}$

- $\mathrm{FS}=$ True, state $\rightarrow \mathrm{EH}$

\section{LTDH state}

When the supply temperature $T_{1}<60^{\circ} \mathrm{C}$, it is not sufficient to heat the water inside the tank to $55^{\circ} \mathrm{C}$ without warming up the return pipe. Hence, it is designed to use $\mathrm{DH}$ to supply basic heating demand up until $T_{1}-10^{\circ} \mathrm{C}$ with level 1 controller automatically adjusting the valve M2 and the electric coil disconnected. The state transits if:

$$
\text { - } T_{2} \geq T_{1}-10^{\circ} \mathrm{C} \text { OR FS }=\text { True, state } \rightarrow \mathrm{EH}
$$

- $T_{1} \geq 60^{\circ} \mathrm{C}$, state $\rightarrow \mathrm{hDH}$ 


\section{EH state}

When there are heat boosting needs, or there is an external fuel shift (FS) signal forcing to shift the energy source, M2 is closed, and the electric relay is closed to use the electric coil instead of DH to supply domestic hot water (DHW). The electric heating (EH) thermostat maintains the DHW temperature at $60^{\circ} \mathrm{C}$ unless a large water draw results in $T_{2}<T_{1}-14{ }^{\circ} \mathrm{C}$, in which case the controller goes back to the LTDH state. The state transits if:

- $\mathrm{FS}=$ False $\mathrm{AND} T_{1} \geq 60^{\circ} \mathrm{C}$, state $\rightarrow \mathrm{hDH}$

- $\mathrm{FS}=$ False AND $T_{1}<60^{\circ} \mathrm{C}$ AND $T_{2}<T_{1}-14{ }^{\circ} \mathrm{C}$, state $\rightarrow$ LTDH

The finite-state machine described above is further illustrated in Figure 22. The FS

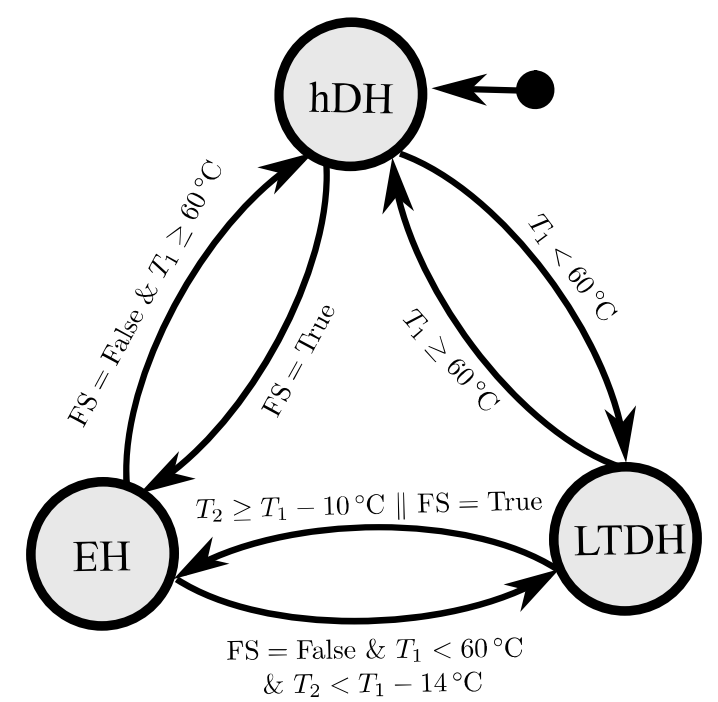

Figure 22: State machine for the level 2 situation-aware controller

signal described above provides the interface for the level 3 controller to shift the heating sources while enabling LTDH. All the measurements available to level 2 are also available for level 3 controller.

\section{Acknowledgement}

We would like to thank Anders Bro Pedersen and Tom Bailly-Salins for supporting to develop the fuel shift platform. This research was part of a project which is funded by the Danish EUDP (Energy Technology Development and Demonstration Programme). Project title: EnergyLab Nordhavn - Smart components in integrated energy systems, project number: 64015-0055. 


\section{References}

[1] H. Lund, S. Werner, R. Wiltshire, S. Svendsen, J. E. Thorsen, F. Hvelplund, B. V. Mathiesen, 4th Generation District Heating (4GDH): Integrating smart thermal grids into future sustainable energy systems, Energy 68 (2014) 1-11. doi:10.1016/j.energy.2014.02.089.

[2] H. Lund, P. A. Østergaard, D. Connolly, B. V. Mathiesen, Smart energy and smart energy systems, Energy 137 (2017) 556-565.

[3] P. Mancarella, MES (multi-energy systems): An overview of concepts and evaluation models, Energy 65 (2014) 1-17.

[4] P. Palensky, D. Dietrich, Demand Side Management: Demand Response, Intelligent Energy Systems, and Smart Loads, IEEE Transactions on Industrial Informatics 7 (3) (2011) 381-388. doi:10.1109/ TII.2011.2158841.

[5] P. J. Douglass, R. Garcia-Valle, P. Nyeng, J. Østergaard, M. Togeby, Smart demand for frequency regulation: Experimental results, IEEE Transactions on Smart Grid 4 (3) (2013) 1713-1720.

[6] A. Thingvad, S. Martinenas, P. B. Andersen, M. Marinelli, O. J. Olesen, B. E. Christensen, Economic comparison of electric vehicles performing unidirectional and bidirectional frequency control in denmark with practical validation, in: 2016 51st International Universities Power Engineering Conference (UPEC), IEEE, 2016, pp. 1-6.

[7] A. Thingvad, C. Ziras, M. Marinelli, Economic value of electric vehicle reserve provision in the Nordic countries under driving requirements and charger losses, Journal of Energy Storage 21 (2019) 826-834.

[8] K. Ahmed, P. Pylsy, J. Kurnitski, Hourly consumption profiles of domestic hot water for different occupant groups in dwellings, Solar Energy 137 (2016) 516-530.

[9] C. Johansson, F. Wernstedt, P. Davidsson, Deployment of agent based load control in district heating systems, in: First International Workshop on Agent Technologies for Energy Systems, Canada, 2010.

[10] E. Guelpa, S. Deputato, V. Verda, Thermal request optimization in district heating networks using a clustering approach, Applied Energy 228 (2018) 608-617.

[11] H. Cai, S. You, J. Wang, H. W. Bindner, S. Klyapovskiy, Technical assessment of electric heat boosters in low-temperature district heating based on combined heat and power analysis, Energy 150 (2018) 938-949.

[12] J. Wang, H. Zhong, Z. Ma, Q. Xia, C. Kang, Review and prospect of integrated demand response in the multi-energy system, Applied Energy 202 (2017) 772-782.

[13] S. Bahrami, A. Sheikhi, Others, From Demand Response in Smart Grid Toward Integrated Demand Response in Smart Energy Hub., IEEE Trans. Smart Grid 7 (2) (2016) 650-658.

[14] D. Wang, H. Jia, K. Hou, W. Du, N. Chen, X. Wang, M. Fan, et al., Integrated demand response in district electricity-heating network considering double auction retail energy market based on demandside energy stations, Applied Energy 248 (2019) 656-678.

[15] A. Thingvad, C. Ziras, J. Hu, M. Marinelli, Assessing the energy content of system frequency and electric vehicle charging efficiency for ancillary service provision, in: 2017 52nd International Universities Power Engineering Conference (UPEC), IEEE, 2017, pp. 1-6.

[16] C. Sandersen, K. Honoré, Deliverables no.: D5.2c \& D5.2d District heating flexibility - short term heat storage in buildings, Tech. rep., HOFOR A/S (2018).

[17] HOFOR, https://www.hofor.dk/.

[18] The Danish Government, The Danish Climate Policy Plan Towards a low carbon society (2013).

[19] S. Frederiksen, S. Werner, District heating and cooling, Studentlitteratur, 2013.

[20] The Danish Transport and Construction Agency, Danish Building Regulations 2015 (BR15) (2015).

[21] Energinet, Specification of requirements and test of FCR-N in DK2 (2017).

[22] Energinet.dk, Ancillary services to be delivered in denmark - tender conditions., http://energinet.dk (2019).

[23] H. Lund, F. Hvelplund, P. A. Østergaard, B. Möller, B. V. Mathiesen, P. Karnøe, A. N. Andersen, P. E. Morthorst, K. Karlsson, M. Münster, Others, System and market integration of wind power in Denmark, Energy Strategy Reviews 1 (3) (2013) 143-156.

[24] Y. V. Makarov, S. Lu, J. Ma, T. B. Nguyen, Assessing the value of regulation resources based on 
their time response characteristics, Tech. rep., Pacific Northwest National Lab.(PNNL), Richland, WA (United States) (2008).

[25] A. Thingvad, Delivery no.: 4.4d Design, development and testing of low-cost controllers for fuel-shift technologies, Tech. rep., Technical University of Denmark (2017).

[26] DS 439:2009, Danish Standards, Code of Practice for Water Supply Installations.

[27] H. Cai, S. You, H. W. Bindner, S. Klyapovskiy, Load Situation Awareness Design for Integration in Multi-Energy System, in: Energy Internet (ICEI), IEEE International Conference on, IEEE, 2017, pp. $42-47$.

[28] H. Cai, S. You, D4.4e1 Validation document on field-data collection from 1101 DHW appliances (small tanks), Tech. rep., Technical University of Denmark (2019).

[29] OASIS, http://mqtt.org/.

[30] V. Lampkin, W. T. Leong, L. Olivera, S. Rawat, N. Subrahmanyam, R. Xiang, G. Kallas, N. Krishna, S. Fassmann, M. Keen, Others, Building smarter planet solutions with mqtt and ibm websphere mq telemetry, IBM Redbooks, 2012.

[31] H. Cai, C. Ziras, S. You, R. Li, K. Honoré, H. W. Bindner, Demand side management in urban district heating networks, Applied Energy.

[32] Varmelast, Heating plans, http://www.varmelast.dk/.

[33] L. Brange, P. Lauenburg, K. Sernhed, M. Thern, Bottlenecks in district heating networks and how to eliminate them - A simulation and cost study, Energy 137 (2017) 607-616. 